\title{
SAÚDE E CRISE DA MODERNIDADE (Caminhos, Fronteiras e Horizontes)
}

\section{André Cezar Médici *}

O objetivo deste texto é discutir algumas tendências da medicina, a partir da análise de sua evolução ao longo do período que, do ponto de vista histórico, caracteriza a modernidade e sua crise. A medicina é, desta forma, avaliada segundo as óticas da economia, das relaçōes do poder, do desenvolvimento científico e tecnológico e da linguagem. A questão da economia remete a análise para a questão dos mercados e das formas de concorrência $\theta$ crescimento capitalista assumidas pela medicina ao longo de sua trajetória. A questão do poder remete a análise das instituiçōes de saúde e das formas de organização do trabalho no setor. A questão da ciência procura avaliar o espectro de formas de produção do conhecimento no setor, bem como seus impactos na cobertura e na eqüidade do acesso às condições de saúde e assistência médica. Por fim, a questão da linguagem marca a análise de como a tecnificação extrema da medicina vai progressivamente caracterizando campos semânticos próprios a cada especialidade, dificultando o uso de teorias totalizadoras para explicar as relações internas no seio da produção de conhecimento no setor.

"O pensamento filosófico é hesitação contínua, muito surda, mesmo quando tem as pomposas garantias dogmáticas. Mesmo quando avança, recua em si mesmo., Diz-se que é uno e ele se despedaça"

(BACHELARD, "Fragmento de um Diário do Homem")

* Coordenador da Área de Políticas Sociais do Instituto de Economia do Setor Público (IESP/SP) 
O controle do corpo e da mente constitui uma das mais antigas aspirações da humanidade. Qualquer que fosse o motivo para tal - poder, prestígio, riqueza material, conhecimento, tranqüilidade espiritual, a busca da cura e da imortalidade, reconhecimento por parte do divino, etc. - dedicar-se à tarefa de prevenir e curar doenças físicas ou mentais tem sido o cotidiano de pessoas, seitas e instituições e, mais recentemente, de indústrias e movimentos sociais.

Apesar dos inegáveis avanços alcançados ao longo desta estratégia, a atenção à saúde, individual ou coletiva, sempre foi obtida de forma assimétrica do ponto de vista social. Até mesmo na caminhada que se inicia com a modernidade e se estende até hoje, muitos êxitos tem sido obtidos na arte de prevenir e curar, mas o progresso técnico em saúde não tem propiciado a incorporação dos segmentos sociais excluídos com a mesma vitalidade que gera inovações nos meios diagnósticos e terapêuticos.

Portanto, o mérito em alcançar controle crescente sobre o corpo e a mente, obtido a partir da medicina moderna, fica obscurecido parcialmente pelo distanciamento progressivo entre populações cobertas, ricas e sadias e populações descobertas, miseráveis e insanas, ao nivel mundial. Em medicina, reproduz-se um velho dilema latente em todos os paradigmas da modernidade, expresso na dicotomia entre "crescimento $x$ distribuição" ou ainda entre "progresso técnico $x$ eqüidade".

Este artigo pretende buscar o mapeamento dos caminhos traçados pela medicina moderna, bem como de suas fronteiras e horizontes, quer do ponto de vista da ampliação do domínio do corpo e da mente, através do conhecimento, da ciência e da técnica; quer no que diz respeito ao alargamento do espectro de acessibilidade aos serviços de saúde. 


\section{OS QUATRO NAIPES DA QUESTÃO}

Segundo Foucault, "a medicina moderna fixou sua própria data de nascimento em torno dos últimos anos do século XVIII"(1). Foi precisamente nesta época que os detentores do saber e da técnica em medicina passaram a refletir sobre sua própria prática, ou mais precisamente, quando a medicina passa a identificar que os fatos novos descobertos a partir de experimentos vinculados a esta prática podem ser acumulados e utilizados numa perspectiva de progresso.

De lá para cá a medicina e seu campo de aplicação - a saúde enveredaram por muitos caminhos, os quais podem ser sintetizados em quatro naipes (2) .

O primeiro naipe - "ouros""- revela a chamada perspectiva de "mercado" da medicina. Não utilizamos o termo "mercantilização" no sentido pejorativo ou negativo que muitos procuram dar. Mercantilização carrega em si, antes de tudo, a idéia de mercado, a qual é reconhecida por todos como a instância máxima das sociedades capitalistas desde o seu nascimento.

O mercado é, antes de tudo, o "locus" onde são trocados os frutos do trabalho humano. Dizer que a medicina é passível de "passar pelo mercado" é reconhecê-la, antes de tudo, como produto social do trabalho dos homens.

É inegável, portanto, a existência de uma medicina privada, "liberal", submetida aos mecanismos individuais e às leis de mercado (3). Mas da mesma

(1) FOUCAULT, M. "O Nascimento da clínica", Ed. Forense Universitária, Rio de Janeiro, $2^{\mathrm{a}}$ ed., 1980, p. $\mathrm{X}$.

(2) Segundo o "Novo Dicionário Aurélio", um dos significados do verbete "naipe" pode ser qualidade, condição, categoria, classe".

(3) Ver sobre este ponto FOUCAULT, M. "A Política de Saúde no Século XVIII", In: "Microfísica do Poder", 
forma, é inegável também a concepção de que o mercado é antes de tudo, uma instância sujeita a estratificação. $E$ dessa forma, discutir a questão da mercantilização da medicina é também discutir o acesso desigual aos serviços de saúde, ou seja, a questão da "eqüidade".

\section{O segundo naipe - "espadas"- representa a questão do poder em}

saúde. O poder envolve, necessariamente dois aspectos: a polftica do Estado, de um lado, e a politica das corporações ou da chamada Sociedade Civil, de outro. A primeira, de uma certa forma, se apóia no "Estado", enquanto estrutura de poder. A segunda se legitima em formas corporativas de poder: profissões (sindicatos), empresas, ramos de conhecimento, movimentos sociais de bairros, movimentos ideológicos em torno de questões coletivas (ecologia, pacifismo, qualidade de vida), partidos polfticos, etc..

O terceiro naipe - "paus" - representa a questão tecnológica (4). A ciência e a técnica tiveram um desenvolvimento particular no campo da saúde e trazem muitas armadilhas para o futuro próximo. Mas não devemos considerar apenas os avanços no conhecimento oficial, legitimados pelos circuitos dominantes do "dinheiro e do poder", para usar a expressão de Habermas. A questão tecnológica envolve o estudo das vias alternativas de construção de conhecimento em saúde, tais como as práticas de medicina e farmacopéia popular, homeopatia e outras mais.

Por fim, o quarto naipe - "copas" - representa o afeto, nossos sentimentos, as formas de expressá-los, a linguagem. A linguagem é fundamental na construção unitária do discurso cientffico da medicina. O nascimento da medicina

Ed. Graal, Rio de Janeiro, $6^{\mathrm{a}}$ ed., 1986, pp. 193-207.

(4) O naipe "paus" pode ser considerado como representação arquetípica da ciência e da técnica, pois caracteriza o primeiro meio de intermediação do homem com a natureza depois das mãos. Os paus foram utilizados como extensão dos braços em diversas formas pelos primatas; como armas, alavancas, artoches, etc.. 
moderna é antes de tudo o nascimento de uma linguagem que procura estabelecer um vínculo entre o saber e a dor; ou melhor, que procura decifrar o código da dor na perspectiva do saber.

Mas da mesma forma em que o estabelecimento de uma linguagem cientffica marca o ponto de criação da medicina moderna é na própria linguagem que vamos encontrar o ponto de mutação, ou o estabelecimento de uma "zona cinzenta" na perspectiva do saber médico. Esta zona cinzenta é fruto de uma crescente segmentação do conhecimento e da prática médica, através de novos "dialetos" que surgem nesse campo de conhecimento, e se expressa não só nos canais oficiais, mas também nos meios alternativos de reprodução dessa prática e desse saber.

Para termos uma visão completa destes quatro naipes, não basta descrevê-los e analisa-los individualmente. É necessário observá-los em jogo, ou seja, em cena e em movimento no curso da história.

\section{A SAÚDE E O MERCADO}

Dois pontos de vista marcam as interpretações sobre as origens da medicina moderna. O primeiro, representado pela corrente do inglês George Rosen (5), diz que a medicina moderna nasce enquanto prática coletiva nas instituições religiosas ou nos governos e que, paulatinamente a organização de clientelas privadas, com o advento do capitalismo, foi desmantelando sua lógica e tornando-a uma ação individual voltada para um mercado de compra e venda de serviços.

Outro ponto de vista diz que a medicina nasceu a partir de uma relação privada e singular entre o médico e o paciente: relação essa que se estabelecia numa

(5) ROSEN, G. "History of Public Health", London, 1958. 
esfera "normal" de compra e venda de senviços; mas uma série de pressões e demandas sociais acabaram por torná-la um bem público voltado para a coletividade.

Na verdade, pode-se dizer que as duas visões são complementares. $O$ caráter "social" da medicina pode ser observado desde a constituição dos Estados Absolutistas Europeus, quando se organiza uma polfica médica, quando se implementam medidas públicas de saneamento e são criados hospitais de atendimento universal, embora, na prática, voltados para indigentes e segmentos pauperizados da população.

Não só no Estado mas também na sociedade civil são encontradas evidências de que, desde as mais remotas origens, existem sistemas de atenção à saúde voltados para a coletividade. É o caso das instituições religiosas, que mantinham hospitais destinados ao atendimento geral, ou ainda das associações de socorros mútuos ou "mutualidades", que desde o tempo das corporações de ofício medievais preocupavam-se em montar sistemas de autofinanciamento dos cuidados de saúde para seus filiados.

Mas independentemente das formas coletivas de organização da atenção à saúde acima descritas funda-se em paralelo uma prática médica voltada para aqueles que podem pagar. Assim, surge o desenvolvimento de um "mercado privado de serviços de saúde", que tem como base de sustentação e qualificação crescente dos profissionais médicos, a criação de uma demanda efetiva de senviços voltados para indivíduos ou familias, lastreada na ampliação das camadas médias da população e a exaltação da relação médico-paciente, enquanto relação liberal, como a forma social e cientificamente mais eficaz de solução dos problemas de saúde.

O mais interessante dessa história consiste na alimentação mútua destas duas lógicas de organização dos sistemas de saúde desde sua gênese. Com efeito, 
o elo de ligação entre elas era o profissional médico que freqüentava muitas vezes os serviços de atendimento geral ou coletivo, ocupando cargos como servidor do Estado desinteressado pelo vil metal, ao mesmo tempo em que mantinha sua clientela entre as familias remediadas e abastadas das cidades como principal forma de remuneração.

Freqüentava as corporações profissionais e cientfficas com seus companheiros e mantinha vínculos com a universidade, o que the garantia o acesso às novas técnicas e procedimentos terapêuticos, bem como aos medicamentos e equipamentos mais modernos. Seu vínculo com o setor público aumentava seu prestigio e realimentava a expansão de seu mercado individual, formando um incessante circuito prestígio - dinheiro - prestígio.

Assim, diferentemente do que muitos médicos costumam pensar, ao se lamuriar de sua crescente condição de assalariamento, a medicina enquanto profissão já nasceu marcada pela heteronomia, na medida em que sempre foi comum ao médico trabalhar e manter vínculos simultâneos na esfera pública e na privada, mesmo que com posições ocupacionais distintas. 0 que mudou, então, na configuração do mercado de serviços de saúde?

A mudança encontra-se no nascimento da empresa médica, fenômeno associado à chamada idade madura do capitalismo, a empresa médica decorre do crescente grau de mercantilização e de assalariamento formal da economia; da redução do espaço do auto-consumo das familias; da ampliação do espaço do capital monopolista no seio das sociedades industriais. São as formas coletivas e "securitizadas" de contrato que a empresa médica vai buscar seu caminho de crescimento.

Logicamente que a empresa médica é mais marcante nas sociedades 
onde as formas coletivas de atenção pública à saúde não se desenvolveram no sentido universal, como é o caso das Health Maintenence Organizations (HMO) nos Estados Unidos e recentemente (apesar de toda a retórica universalista da "reforma sanitária") da medicina de grupo no Brasil. Mas de qualquer forma é nos contratos coletivos de seguro-saúde com as empresas e, em menor importância, com as familias, que o mercado de serviços de saúde se expande, representando hoje no Brasil um volume de recursos de quase US $\$ 2,0$ bilhões.

O relacionamento básico da empresa médica com os médicos não é o do assalariamento clássico, mas sim, o pagamento por unidade de serviço, diagnóstico ou procedimento. Com isto, a medicina moderna ampliou o próprio sentido da heteronomia do trabalho médico, ao criar vínculos que passam desde o assalariamento clássico no setor público até o trabalho liberal no consultório, passando por uma relação de compra de atos médicos pela empresa médica (6).

Sob a ótica da demanda, a questão do mercado de serviços de saúde passa, obviamente, pela segmentação de clientelas, especialmente nas situações onde os serviços públicos são caracterizados pela má qualidade. Nestes casos, a diversidade de acesso aos serviços privados crescentemente mais qualificados, por parte dos que podem pagar, representa graus diferenciados de acesso a continuidade da vida, ou ainda, patamares estratificados de cidadania.

A modernidade trouxe outra conseqüência importante no plano da mercantilização: a chamada industrialização da saúde. Até o século XIX a divisão do trabalho médico não tinha sido suficiente para separar totalmente a confecção de remédios e equipamentos médicos da clínica. Neste sentido o processo de trabalho médico determinava, em grande medida, a natureza dos insumos e equipamentos utilizados.

(6) Ver DONNANGELO, M.C. e PEREIRA, L. "Saúde e Sociedade", Ed. Duas Cidades, São Paulo, 1976. 
O desenvolvimento de produtos farmacêuticos e equipamentos médicos em escala industrial trouxe não só uma autonomia destes setores frente ao trabalho médico, através do acesso ao mercado pelo marketing voltado para o auto-consumo, mas também colocou o próprio processo de trabalho médico subordinado as inovações no campo da indústria de insumos e equipamentos. Com isso, o mercado de serviços de saúde tornou-se adicionalmente um segmento do mercado destes produtos industriais.

\section{A SAÚDE E O PODER}

O poder é entendido aqui como o espaço das instituições, do Estado e das formas coletivas de pressão e representação social. A instância dinâmica do poder é a polftica. A saúde só começou a ser objeto de polftica a partir do Renascimento, seja através do Estado, seja através das instituições caritativas, religiosas, etc..

Podem ser reconhecidas três fases da evolução da saúde enquanto politica na modernidade (7). A primeira fase assistencialista - caracterizou a polftica de saúde até meados do século XIX. Sua tônica era basicamente a de voltar a atenção à saúde para as populações mais empobrecidas e carenciadas. Desenvolveu-se institucionalmente em organizações leigas ou religiosas que se destinavam a fins múltiplos, tais como distribuição de alimentos, educação e proteção a crianças carentes, etc.. São exemplos destas instituições aquelas que funcionavam sob a égide das "poor laws" ou ainda as "work-houses" na Inglaterra. Nas palavras de Foucault,

(7) Ver MÉDICl, A.C. "Crise Econômica e Políticas Sociais: O Caso da Saúde no Brasil". Tese de Mestrado apresentada ao Instituto de Economia da UNICAMP, em julho de 1988, Campinas, mimeo., 398p. Ver especialmente a Introdução. 
"Na figura do pobre necessitado que merece hospitalização, a doença era apenas um dos elementos em um conjunto que compreendia a enfermidade, a idade, a impossibilidade de encontrar trabalho, a ausência de cuidados" (8)

Embora o "assistencialismo" em saúde tenha nascido de forma integrada a outras politicas sociais, tendo nas instituições da sociedade civil a sua origem, pode-se dizer que o Estado sempre foi um grande provedor de serviços assistenciais de saúde, haja vista as medidas relacionadas a distribuição de medicamentos nos reinados de Luís XIV a Luís XVI (França), as polfticas de saúde e vigilância englobadas no conceito de polícia médica (Alemanha) e as próprias "poor laws" (Inglaterra).

O final do século XVIII marca o surgimento de uma consciência em torno do assistencialismo. Decorrência das mudanças na esfera econômica e social que caracterizam o capitalismo industrial e a possibilidade de utilização generalizada da força de trabalho no processo produtivo, independentemente de sua qualificação, a nova consciência atribuía ao assistencialismo, o ócio da população e a despesa pública improdutiva e pregava a necessidade de eliminá-lo com vistas a construção de uma sociedade mais laboriosa e rica. A derrubada das "poor-laws" inglesas em 1848 pelo parlamento é a expressão máxima dessa consciência.

As novas aspirações do poder - o Estado e as classes sociais hegemônicas - no campo da saúde, deslocam-se do universo da pobreza desassistida para o universo do trabalho" (9) que vai se erigir uma nova modalidade de politica de saúde.

A segunda fase - previdencialista - inicia-se com a formação de organizações mutualistas no seio de profissionais artesãos, tendo em vista cobrir, sob

(8) FOUCAULT, M. "A política de Saúde no Século XVIII", op. cit., p. 195.

(9) Sobre a utopia de uma sociedade de trabalho, ver HABERMAS, J. "A nova Intransparência". In: Novos Estudos CEBRAP, n² 18, setembro de 1987, pp. 103-114. 
a forma de seguro, aspectos ligados à saúde e à previdência para grupos de trabalhadores que se organizavam e auto-financiavam, mediante cotização, estes programas. Este modelo foi repetido nas empresas (com participação de trabalhadores e patrões no financiamento) e posteriormente generalizado para qualquer trabalhador formal (como na Alemanha recém unificada por Bismark), com a participação adicional do Estado no financiamento.

O previdencialismo se extende da segunda metade do século $\mathrm{XIX}$ até finais da primeira metade do século XX como forma hegemônica de política de saúde. Seu advento não eliminou a política assistencialista, embora a tenha limitado a determinados segmentos e clientelas da população.

O previdencialismo, como forma de política social e de saúde foi um dos principais elementos que marcam o fortalecimento de uma sociedade do trabalho. Nesta perspectiva, apenas trabalhadores e suas familias eram dignos de receber uma atenção médica decente e diferenciada daquela recebida por pobres, vagabundos e indigentes.

É verdade que o Ocidente (especialmente os países europeus) vivenciou uma generalização do assalariamento após o advento do capitalismo monopolista. Com isso, extendeu-se o acesso de quase toda a população destes países às formas previdencialistas de atenção à saúde. $\mathrm{O}$ advento das duas guerras mundiais abalou a consciência de que saúde seria somente um direito de trabalhadores. Em circunstâncias marcadas pela calamidade, como a guerra, não haveria distinção entre aqueles que deveriam ser atendidos pelos sistemas de saúde existentes.

"Consciente desse problema, o Governo Britânico, em 10 de junho de 1941 pediu a "Sir" William Beveridge que se encarregasse, respeitando a interrelaçāo de planos, de um exame dos projetos nacionais, já existentes, de previdência social e serviços afins, inclusive a remuneração dos trabalhadores, e apresentasse soluções. Após 18 meses de trabalho intenso, em 20 de novembro de 1942, "sir" William Beveridge 
apresentou seu relatório. Suas recomendações, certamente, excederam em muito as expectativas do Governo". (10)

Com efeito, o advento do Plano Beveridge marcou uma nova era na atenção à saúde: a fase universalista. Nesta nova concepção, a saúde deixa de ser um atributo dos trabalhadores para ser direito do cidadão, independente de sua inserção no mercado de trabalho e de sua condição social. A gratuidade na prestação dos serviços, a universalidade de cobertura e a integralidade do acesso aos serviços, bem como a montagem de um sistema de financiamento calcado em impostos universais e não em contribuições sociais, passa a ser a tônica dessa nova estrutura da polftica de saúde na Europa Ocidental.

Deve-se, no entanto, levar em consideração a dificuldade de chegar ao universalismo na atenção à saúde em todas as sociedades contemporâneas. As condições levaram as sociedades européias a este tipo de politica de saúde foram muito especfficas e podem ser sintetizadas em três pontos:

a) - Generalização do assalariamento formal. Mais de $90 \%$ da classe trabalhadora no momento da passagem do previdencialismo ao universalismo era composta por assalariados formais nos países europeus. Isto minimizou o esforço financeiro em custear uma politica de saúde universal a partir do Estado, com um "mix" de contribuições sociais e tributação ordinária;

b) - Elevação da consciência politica das massas e estabelecimento de fortes pressões sociais por melhores condições de vida;

c) - Elevação brutal da produtividade e forte crescimento econômico nos anos

(10) SIGERIST, H.E. "De Bismark a Beveridge: Desenvolvimento e Objetivos da Legislação de Previdência Social". Este texto, hoje clássico, publicado pela primeira vez no Bulletin of the History of Medicine de abril de 1943, foi traduzido e reeditado em português, sob forma mimeografada, na série "PESESPEPPE - Textos de Apoio", n 6, da ENSP/FIOCRUZ nos anos sessenta. 
subseqüentes, propiciando o surgimento de ganhos ainda maiores na qualidade de vida ao longo dos chamados anos dourados do welfare state;

d) - Existência de um setor privado supletivo de razoáveis proporções voltado para os segmentos da população que pudessem pagar por uma atenção diferenciada ou por cuidados mais sofisticados e individualizados.

Tais condições estavam ausentes nos planos subdesenvolvidos e, portanto, a fase universalista da política de saúde, em que pese sua importância, é fenômeno bastante restrito em termos mundiais.

Cabe comentar ainda algumas questões de natureza geral sobre as três fases das políticas de saúde. A primeira delas é que a hegemonia do universalismo não eliminou a existência das outras formas - assistencialista e previdencialista - no contexto mundial. Mesmo nos países onde é hegemônico o universalismo, a politica e a filosofia previdencialista sobrevive nas empresas de maior porte e complexidade onde é possível encontrar planos de saúde especiais custeados por empregados e pela própria empresa e voltados para o mercado privado de serviços de saúde.

O que se observa na prática é que a lógica previdencialista desaparece no público, mas ressurge no privado, trazendo efeitos líquidos no aumento da estratificação social da atenção médica. Na medida em que são criadas formas cada vez mais sofisticadas de diagnóstico e terapia disponíveis apenas no setor privado, o "universal" garantido pelo público transforma-se simplesmente num "piso mínimo" de cidadania social.

As crises econômica e fiscal dos anos setenta e oitenta e seus impactos no Estado e nas políticas sociais trouxeram perspectivas de redução deste piso mínimo, mesmo nos países europeus. As estratégias de flexibilização, como é sabido, reduziram, em muitos casos, o porte dos programas sociais dos países 
centrais. Com isso, o setor privado aumentou seu espaço mediante o crescimento de uma atenção diferenciada e tecnologicamente mais moderna (11).

Na medida em que aumenta o espaço entre a atenção à saúde mais moderna do setor privado, voltada para aqueles que podem pagar, e o "patamar mínimo" do setor público, reedita-se o assistencialismo; não aquele voltado para os despossuídos e miseráveis, mas uma forma de "assistencialismo" baseada numa atenção à saúde de menor qualidade voltada para os segmentos sociais com menos recursos. Este é o caso dos EUA, por exemplo, onde programas como o"medicare" e o "medicaid" destinam-se a segmentos desprotegidos da população, mas a atenção médica da maioria consiste em planos de seguro privados - individuais ou pagos parcialmente pelos seus empregadores - ofertados e operacionalizados pelas Health Maintenance Organizations.

Uma segunda questão diz respeito ao fato de que em países em desenvolvimento, como o Brasil, vive-se uma situação ainda mais díspar: um discurso universalista: o da reforma sanitária; uma prática previdencialista para o setor formal do mercado de trabalho: a "real politique" do INAMPS e do SUS e um segmento - de mais de um terço da população do país - composto por pessoas pobres e totalmente descobertas de qualquer mecanismo de seguridade social; população-alvo das politicas de corte assistencialista.

Uma terceira questão remete ao retorno de uma ideologia neo-liberal, crftica ao Estado e aos seus mecanismos de proteção social. Tal ideologia só aceita a política de saúde assistencialista voltada aos que não podem pagar, e mesmo

(11) Até mesmo na Itália, onde há vinte anos foi implantada uma Reforma Sanitária calcada na universalização do acesso, tendo o Estado como organizador do sistema e principal prestador de serviços, observa-se hoje forte crescimento do setor privado autônomo no seio da atenção a saúde das famílias e das empresas. Esta questão foi discutida no "Encontro ftalo-brasileiro de saúde", realizado em Salvador entre 18 e 21 de junho de 1989. 
assim com restrições. Para os que podem pagar caberia o mercado. Isto explica o programa de privatização dos governos conservadores europeus na virada dos anos setenta para os oitenta. Explica também o reflorescimento da medicina de empresa, organizada sob novas bases técnicas e administrativas no seio dos países desenvolvidos.

O desenvolvimento de uma polftica de saúde universalista, como parte do Welfare State, bem como sua recente crise, marcam o auge e o esgotamento da utopia de uma sociedade do trabalho. Mas as respostas conservadoras a essa crise nem sequer chegam a vislumbrar as saídas possíveis. Não é destruindo o Estado ou adequando esse Estado à antiga dimensão liberal que resolve-se uma crise, que se esgota no trabalho enquanto motor dos ideais de desenvolvimento e crescimento. Nas palavras de Habernas:

"O projeto do Estado social voltado para si, dirigido não apenas à moderação da economia capitalista mas também à domesticação do Estado mesmo, perde, porém, o trabalho como seu ponto central de referência. Isto é, já não se trata de assegurar o emprego por tempo integral à condição de norma (...) As sociedades modernas dispõe de três recursos que podem satisfazer suas necessidades no exercício do governo: o dinheiro, o poder e a solidariedade. As esferas de influência desses recursos teriam de ser postas em um novo equilibrio (...) O poder de integração social da solidariedade deveria ser capaz de resistir às forças dos outros dois recursos: dinheiro e poder administrativo (12)

A proposta de Habernas, mesmo que calcada na realidade dos países desenvolvidos, passa pela necessidade de reequilibrar as relações entre mercado, Estado e interesse coletivo. As formas de representação do chamado "interesse coletivo" avançaram muito ao longo dos anos. Os sindicatos e os partidos políticos duas grandes forças propulsoras dos ideais de uma "sociedade de trabalho" - foram os principais pilares das conquistas obtidas no campo dos direitos à saúde; do

(12) HABERMAS, J. "A Nova Intransparência", op. cit, p. 112. 
previdencialismo ao universalismo. Mas nos anos recentes a questão da saúde não tem sido mais uma bandeira unitária destas duas instituições tradicionais de representação.

O interesse coletivo na questão da saúde organiza-se hoje de forma fragmentária em distintas instâncias neo-corporativas, como movimentos ecológicos, movimentos de bairro, movimentos pacifistas, movimentos pró-saúde alternativa, movimentos eclesiais de base, movimentos de defesa do consumidor e da qualidade de vida, etc. Tais movimentos assimilam, cada um a seu modo, a questão da saúde como parte de sua visão de mundo.

Ao mesmo tempo, as corporações tradicionais de profissionais de saúde, sindicatos, donos de hospital e funcionários públicos ligados ao setor continuam a desencadear formas de fazer representar seus interesses.

Os desafios postos pela crise da modernidade quanto a questão do poder em saúde passam, obviamente, por um equilíbrio democrático entre esta pluralidade de interesses. Tal equilibrio, por sua vez torna imprescindível à compreensão de que o público nem sempre é social e de que o privado e o interesse coletivo podem ser harmônicos.

\section{A SAÚdE E A CIÊNCIA}

Não há como separar a questão cientffica e tecnológica em saúde da representação social do processo saúde-doença, o qual passa por diversas formas no curso da história. A ciência e a técnica estão presentes nas formas pelas quais a doença é percebida, medicamente investida, isolada ou distribuída segundo os meios de cura disponíveis na sociedade. 
No entanto, prevenir e curar sempre foram duas lógicas distintas de abordagem da questão da saúde. Cada uma destas lógicas detém formas particulares de incorporação da ciência e do progresso técnico.

Comecemos pela instituição basilar destinada à cura na sociedade moderna: o hospital. Esta instituição, até antes do século XVIII, era um mero depositário de doentes pobres cujas perspectivas de cura não mais existiam. Os doentes recebiam apenas roupas e comida, mas nunca visitas médicas acompanhadas de observação. O hospital era não uma instituição de cura, mas um corredor entre a vida e a morte e o pessoal que trabalhava nos hospitais era geralmente composto por missionários e religiosos, cujo trabalho principal era preparar espiritualmente o doente para o "vida eterna". De acordo com Foucault:

"O hospital como instrumento terapêutico é uma invenção relativamente nova, que data do fim do século XVIII. A consciência de que o hospital pode e deve ser um instrumento destinado a curar aparece claramente em torno de 1780 e é assinalada por uma nova prática: a visita $\Theta$ a observação sistemática dos hospitais" (13)

A utilização do hospital como espaço para a cura ocorre em simultâneo à introdução de uma organização disciplinar nesta instituição, conjuntamente com a instauração de um "poder médico" em seu interior. A disciplina e a hierarquia "militar" no hospital permitiram aumentar o controle, introduzir a vigilância dos doentes, bem como um registro contínuo de seu estado de saúde. A introdução da disciplina permitiu transformar o hospital em meio para a investigação cientf́ica. É nele que começam a ser conhecidos os efeitos e conseqüências de determinadas terapias sobre algumas doenças.

A medicalização do hospital propiciou a análise aplicada ao estudo de fenômenos fisiológicos, em retorno aos escritos hipocráticos enquanto prova do

(13) FOULCAULT, M. "O Nascimento do Hospital". In: "Microfísica do poder", op. cit., p. 99 
"risorgimento" do interesse pelo estudo da clínica, a união da medicina com a cirurgia (14), a reorganização das escolas clínicas e a introdução dos estudos de anatomia patológica. É nos hospitais que os cadáveres vão ser dissecados, depois de um longo período de obscurantismo religioso que impedia o desenvolvimento da ciência.

O método cientffico utilizado em medicina baseava-se na observação, seguindo a orientação hipocrática da medicina antiga. Da observação nasce a analogia. Era necessário realizar um conjunto quase interminável de observações e comparações até que fossem identificados os sintomas. Os sintomas eram hierarquizados e classificados segundo critérios determinados.

Assim, observação, analogia, identificação e classificação foram "os quatro pontos cardeais" da construção do conhecimento em medicina clínica. Esta metodologia permitiu, com o tempo, a utilização de equipamentos para a obtenção de exames. $O$ exame (através de equipamentos de imagem, som, análise clínica de laboratório de partes e excrementos produzidos pelo corpo) permitiu estender a observação a pontos onde ela era inacessível ao "olho nu".

A medicina de cura também teve seu desenvolvimento cientffico e tecnológico associado ao esforço individual de médicos e boticários empenhados em descobrir novos equipamentos, terapias e remédios, mas foi no hospital que a ciência médica encontrou seu esboço de reprodução e seu laboratório de testes.

Quanto à prevenção, os avanços iniciais ocorreram no campo da higiene. As medidas de saneamento dos portos, para efeitos de reduzir os riscos

(14) Antes do século XVIII, as corporações de ofício dos médicos eram separadas da dos cirurgiōes e havia uma certa disputa entre estes profissionais. 
associados ao comércio internacional e a criação de infra-estrutura de água e esgoto nas cidades, conjuntamente com vigilância dos hábitos de higiene pelos governos, tiveram fortes efeitos na redução da mortalidade nas cidades.

Posteriormente às descobertas no campo da imunização associadas a Pasteur e às campanhas de vacinação e erradicação das grandes endemias trouxeram êxitos ainda maiores. Pode-se dizer que na passagem do século XIX para o século $X X$, a medicina preventiva contribuiu muito mais do que a medicina curativa no prolongamento da vida média da humanidade.

Mesmo assim, a prevenção e a saúde pública sempre foram considerados os "ramos" pobres da medicina e as inovações neste campo, apesar de associadas aos estudos de imunologia e biologia, tiveram um ritmo mais lento do que o observado na medicina curativa e na produção de fármacos, equipamentos e medicamentos. Isto porque a circulação de recursos monetários em saúde sempre esteve associada à medicina curativa e os hospitais, empresas médicas e indústrias de insumos e equipamentos médicos têm trabalhado dinamicamente suas inovações tecnológicas movidos pelo lucro.

Poucas são as pessoas que se dispõe a pagar por "prevenção" em saúde. Foi preciso que o Estado tomasse conta da questão e tornasse a vacinação obrigatória, para que a população ganhasse o hábito de se prevenir contra doenças evitáveis por imunização. Em virtude disso, são poucas as empresas que têm se dedicado a medicina preventiva. A criação de conhecimento e a difusão cientffica e tecnológica em medicina preventiva tem sido, basicamente papel do Estado e das Universidades.

Destacam-se ainda os avanços ocorridos na psiquiatria e na psicanálise. 
Antes do século XVIII, a loucura não era encarada como um mal sistematicamente passivel de internação. Excluindo-se os casos onde o comportamento agressivo era freqüente, os loucos conviviam com suas familias sem maiores problemas.

A terapêutica utilizada para combater a loucura consistia em criar elementos de realidade na vida dos loucos, o que passava por colocá-los em contacto com a natureza onde, na perspectiva da época, "a verdade imutável" estaria presente e, ao mesmo tempo, distante da vida artificial das cidades. Passeios, retiros, viagens em locais não urbanizados e apraziveis eram sempre vistos com bons olhos pelos terapeutas da época. Esta forma de encarar a terapia da loucura influenciou a própria concepção arquitetônica dos hospicios, onde era comum estes terem janelas voltadas ou para campos e paisagens ou para pátios internos cheios de vegetação.

A prática sistemática da internação dos loucos inicia-se no século XIX, quando começam a ser exigidos socialmente padrōes mais rígidos de comportamento pelas normas sociais. Esse enrijecimento das normas de conduta coincide com a afluência das sociedades urbano-industriais, onde o espaço coletivo se agiganta frente ao espaço doméstico, em função da disciplina imposta pelas instituições de trabalho e pela convivência social determinada por regras e normas bem definidas pelo poder público.

O hospital psiquiátrico que surge no século XIX procura aplicar os mesmos métodos de construção do conhecimento e de cura utilizados pelos hospitais voltados para outros males. Todo um esforço é realizado na construção de quadros clínicos da loucura e na classificação dos distúrbios mentais. Mas, diferentemente das demais enfermidades, as doenças mentais não entram em processo de tratamento com a aceitação passiva de seus portadores, tal como acontece com as demais doenças. 
No hospital de clínica geral não há, aparentemente confronto. Médicos, funcionários e pacientes parecem ter o objetivo comum de cura. Nos hospícios, a situação é bem distinta. Entre o médico e o paciente há, antes de tudo, uma estratégia de submissão do segundo ao primeiro, dado que nem sempre o paciente aceita sua cura. Um conflito de poder se estabelece e a dominação, quando alcançada. quase nunca se dá pelo consenso. Assim, o hospital psiquiátrico transforma-se também em "locus" de conflito e confronto; de vencedores e vencidos (15)

Em função de sua natureza, a terapeutica da loucura muitas vezes vai além do permitido pela dignidade humana. Dado que a fala ou a denúncia de um louco não tem crédito no sistema de valores sociais, tudo é permitido de ser feito. Todos esses problemas fazem com que a psiquiatria e os hospícios tenham sido, desde cedo, instituições onde precocemente nascem movimentos crfticos e alternativos.

A critica feita pela anti-psiquiatria passa pela hipótese de que as instituições asilares e os métodos psiquiátricos provocam um acirramento do quadro clínico da loucura. Passam, também, pelo fato de que, se o poder médico nas instituições tradicionais de saúde já é tido como excessivo, é nos hospitais psiquiátricos que se verifica o verdadeiro abuso do poder médico.

Com base nestas criticas surgem, desde o final do século passado, algumas propostas de despsiquiatrização, as quais passam pela supressão do poder médico, pelo controle de doentes mentais através de psicocirurgia ou da psiquiatria farmacológica ou ainda pelo retorno do paciente ao seio familiar. Embora muitas

(15) Segundo Esquirol, um, dos precursores da prática de internação de doentes mentais, existem cinco motivos para o isolamento dos loucos: 1) garantir a segurança pessoal do louco e de suas famílias; 2) liberá-los das influências externas; 3) vencer suas resistências pessoais; 4) submetê-los a um regime médico; 5) impor-Ihes novos hábitos intelectuais e morais 
destas propostas sejam contraditórias, pode-se dizer que o tratamento da loucura em hospitais psiquiátricos é, hoje em dia, um dos campos das ciências da saúde onde o conhecimento e a prática encontram-se menos unitários ou ainda mais despedaçados.

As descobertas de Freud, com a psicanálise, trouxeram outros efeitos no campo da despsiquiatrização. A psicanálise mostrou-se eficaz no tratamento não asilar de muitos distúrbios psíquicos. Mas sua principal contribuição foi efetivamente colocar o acesso das pessoas as razões de seus traumas e tensões do cotidiano.

Outro grande mérito da psicanálise foi proporcionar a possibilidade de "prevenção" de doenças mentais colocando as pessoas comuns, de certa forma, capacitadas a buscar um auxilio aceitável pela sociedade - o do analista - quando detectam angústias ou mudanças de comportamento.

Boa parte da leitura psicanalítica das doenças mentais levava em conta que, apesar da possibilidade de existência de pré-disposições a determinadas doenças mentais (identificadas pela ascendência familiar), grande parte destas são adquiridas pela violência do cotidiano. No entanto, estudos mais recentes no campo da genética tem identificado em certos cromossomos a pré-disposição a determinados tipos de doenças mentais.

A relação entre tecnologia e processo de trabalho em saúde tem se dado de forma distinta do que vem ocorrendo em outros ramos de atividade. O progresso técnico foi entendido como meio de poupar força de trabalho. Em saúde, no entanto, podemos identificar duas formas de atuação do progresso técnico: 
a) nos meios de diagnóstico e terapia;

b) na cirurgia e na relação ambulatorial de atendimento médico

No primeiro caso, se observa que o progresso técnico tem atuado no sentido convencional: o de economizar força de trabalho. A automação dos laboratórios de análises clínicas, através da criação de processos que permitem leitura, classificação e análise das amostras de sangue por computador reduziu muito o emprego de laboratoristas nos últimos anos. O mesmo ocorre no setor de imagem, onde equipamentos mais modernos de raio-X têm eliminado mão-de-obra, tanto na operação do equipamento como na revelação da chapa.

O mesmo não se verifica no processo de trabalho médico, seja no ambulatório, seja na cirurgia. Os novos equipamentos utilizados para melhorar um determinado diagnóstico, como é o caso de tomógrafos computadorizados, não eliminam o médico e até criam um novo tipo de profissional para fazer funcionar este equipamento.

A tecnologia em saúde só tem permitido a redução do emprego quando é aplicada em processos de trabalho de fluxo contínuo. 0 mesmo não ocorre quando a tecnologia se aplica em processos de fluxo descontínuo, como é o caso de consultas ou cirurgias, por exemplo (16)

Algumas evidências mais recentes mostram a existência de um espaço para substituir a força de trabalho em saúde por capital, mediante a transformação de

(16) Entende-se por processos de trabalho de fluxo contínuo aqueles que, ao se caracterizarem por tarefas encadeadas, repetitivas e rotineiras, permitem uma "padronização" e, conseqüentemente, uma posterior "automação", nos moldes tradicionais da indústria fordista. Analogamente, processos de trabalho de fluxo descontínuo são aqueles cujas tarefas não são encadeadas; onde cada passo é um caso. Acredita-se que a informática associada ao processamento ótico trará uma "verdadeira revolução" na automação de processos de fluxo descontínuo. 
processos de trabalho de fluxo descontínuo para contínuo, como é o caso das cirurgias, ou até mesmo automatizando rotinas associadas a processos de trabalho e fluxo descontínuo (como consultas).

No campo da cirurgia, cabe mencionar que os meios modernos de diagnóstico a partir de tecnologias de imagem (tomógrafo, ultrassonógrafos, etc.) permitem obter pré-diagnósticos bem precisos no que tange a localização de tecidos ou órgãos a serem submetidos a intervenções cirúrgicas. Ao mesmo tempo, o processo de robotização já utilizado em muitos ramos de atividade, poderá permitir, num futuro não muito distante, acumular informações e dispor da leveza de movimentos necessários a realização de intervenções cirúrgicas.

No segundo caso, existem softwares desenvolvidos pela própria Organização Mundial da Saúde que permitem, com a entrada necessária de informações e resultados de exames (se necessário), fazer o diagnóstico e a prescrição de medicamentos para todos os tipos de doença existentes na Classificação Internacional de Doenças (CID).

Logicamente que o processo técnico em saúde cria a necessidade de incorporar, a cada ano, uma imensa massa de informações para os Bancos de Dados acessados por esse software. A criação futura de meios mais baratos e condensados de armazenamento de grandes massas de informação permitirá colocar tal tecnologia à disposição não apenas de médicos, mas também de outras pessoas que não detenham necessariamente formação em saúde.

Estes dois exemplos mostram que existem perspectivas, não apenas de uma redução, mas também de um redefinição do trabalho médico a partir destes processos.

A tecnologia do "laser" e do ultrassom tem permitido eliminar 
intervenções cirúrgicas em determinados procedimentos. A tecnologia de materiais vem criando órgãos artificiais que permitem a substituição de partes do corpo humano, através de órteses e próteses. 0 desenvolvimento recente da micromecânica tem criado motores da espessura de um fio de cabelo, capazes de desobstruir artérias e evitar riscos de doenças cardiovasculares sem cirurgia, a partir de monitoramento remoto. A informática permite a criação de "plulas inteligentes", capazes de medir "in loco" a condição de saúde e ministrar a quantidade certa de medicamento requisitada pelo organismo.

No campo da biotecnologia e da engenharia genética tem-se alcançado grandes progressos que poderão aumentar a importância da prevenção e individualizar a ação preventiva, munindo cada indivíduo com todas as informações necessárias sobre suas predisposições (seu mapa genético) a determinadas doenças.

A tecnologia da prevenção tem avançado bastante. $O$ advento das empresas médicas e a generalização seguro-saúde tem tornado atraente a utilização da prevenção como forma de evitar uma maior freqüência de consultas e internações, as quais oneram os custos das empresas médicas que operam sob a forma de seguro. A prevenção permite não só reduzir os custos, como também tornar mais baratas as mensalidades e, portanto, mais competitivas as empresas médicas no mercado.

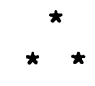

Apesar de todos esses pontos positivos, as novas tecnologias em saúde trazem uma série de implicações negativas, cabendo destacar: 
a) Custos crescentes - Estudos feitos por lan Gough (17) demonstram que existem quatro elementos que têm aumentado os custos da atenção médica na modernidade: tecnologia, ampliação da cobertura populacional, envelhecimento da população e novas modalidades de atenção médica.

b) Menor Acessibilidade - $\mathrm{Na}$ medida em que a atenção médica torna-se progressivamente mais cara, menor a possibilidade de aceso dos segmentos despossuídos, especialmente nos países do terceiro mundo, o que traz desniveis sociais no próprio acesso a manutenção da vida;

c) Maior Controle Individual - As novas descobertas no campo da engenharia genética permitirão selecionar previamente os individuos de acordo com as suas aptidões e suas tendências delimitadas no mapa genético. Ao mesmo tempo em que isso traz possibilidades para as empresas na seleção de pessoal, acarreta em grande perda da liberdade individual.

A questão cientifica e tecnológica em saúde engloba também o estudo da chamada "medicina alternativa", a qual não é unitária, mas sim bastante fragmentada, envolvendo temas como a homeopatia, acupuntura, farmacopéia popular, etc.. Apesar das práticas alternativas serem bastante antigas, elas crescem no seio das próprias sociedades capitalistas ao longo dos anos sessenta e setenta. 0 crescimento destas práticas não se prende apenas aos aspectos técnicos, mas também aos ideológicos. $O$ fato de serem mais baratas, não estarem associadas a hegemonia hospitalar e não trazerem em grande parte os efeitos colaterais da medicina oficial, passaram a ser grandes fatores de atração das camadas médias urbanas para estas práticas. A elas associavam-se também aspectos que transmitiam maior afetividade no processo saúde-doença, distinguindo-as da frieza da relação médico-paciente existente nas instituições ambulatoriais e hospitalares.

(17) GOUGH, lan, "The Political Economy of Welfare State", Mcmillan, London, 1982. 
Vale comentar, no entanto, que boa parte destas práticas passou a ser absorvida pelas sociedades de mercado, pela indústria e pela mídia eletrônica, fazendo com que até mesmo o rótulo de "alternativa" a elas associado seja questionável.

Outro ponto a destacar diz respeito a chamada "medicina simplificada" ou ainda a "atenção primária à saúde", que tem sido ventiladas por organismos internacionais como a Organização Panamericana da Saúde ou a Organização Mundial da Saúde como a solução tecnológica para os males dos países do terceiro mundo. Partindo da concepção de que estes países têm um quadro nosológico distinto das nações desenvolvidas, os adeptos dessas estratégias propõe uma medicina sem sofisticação tecnológica, com forte conteúdo de prevenção e educação sanitária, baseada em agentes comunitários e médicos de "pés-descalços".

Como se sabe, estes países passaram nas duas últimas décadas por um intenso processo de urbanização. Apesar da grande participação das chamadas "doenças da pobreza", o perfil de morbi-mortalidade dos países do terceiro mundo apresenta hoje forte presença das chamadas doenças crônico degenerativas, como as cardiopatias, as neoplasias, os acidentes e as mortes violentas. Tudo isto fica agravado pela pobreza reinante e pelo alto índice de concentração de renda existente.

Ao que tudo indica, portanto, a questão da ciência e da tecnologia em saúde não pode ser discutida sem se pensar na eqüidade. A medicina simplificada não é a panacéia para todos os males dos países subdesenvolvidos. A ênfase em sua utilização sem pensar na incorporação de tecnologia de ponta poderá fazer com que os diferenciais entre os padrões de atenção à saúde do centro e da periferia se tornem, até mesmo, intransponíveis. 


\section{A SAÚdE E A LINGUAGEM (À GUISA DE CONCLUSÃO)}

Ao tentar decifrar a linguagem da dor, a medicina é a ciência que mais se aproxima do corpo. Ela cria uma relação de autoridade com o corpo; relação essa cujo argumento interfere fortemente na dinâmica moral e nos atos volitivos dos homens. Diz-se que um indivíduo está doente e a cura depende da mudança de seus hábitos. A insubordinação pode significar pena de morte.

Mas a medicina pode ser usada, também, como um instrumento de controle do corpo (e não só de cura). Ela pode evitar efeitos indesejáveis (como uma insônia ou o seu inverso, o sono em excesso) e dar segurança aos indivíduos para buscar determinados prazeres da vida. $O$ acesso aos meios contraceptivos propiciado pela medicina moderna é uma das formas de permitir a derrota consciente do determinismo biológico pelo puro prazer.

Ao decifrar a linguagem do corpo, a medicina mostra que, tanto a ameaça de Tanatus como o regozijo de Eros estão em suas perspectivas. Mas para a linguagem do corpo se afirmar enquanto discurso cientffico foi necessária uma longa caminhada. Foi necessário romper os véus místicos e religiosos que separavam, em primeira instância, o homem do indivíduo (Locke) e, posteriormente, o indivíduo de seu próprio corpo.

Mesmo rompidos esses véus, os caminhos traçados para construir uma linguagem cientffica da medicina não se estabeleceram uniformemente. Hoje, o corpo que conhecemos, suas partes constitutivas, seus órgãos e funções, nada mais são que mapas anatômicos criados para entender e classificar o universo da representação e especialização das doenças e dos meios de diagnóstico e terapia. Esses sistemas de representação não são necessariamente iguais, quando se confronta a "anatomia patológica" ocidental com o "do-in" oriental, por exemplo. 
Trata-se de campos semânticos distintos que, com algumas semelhanças e muitas diferenças falam de um mesmo objeto: o corpo.

A medicina ocidental moderna pensou estar construindo uma ciência única, composta por elementos teóricos da biologia, da fisiologia e de outros campos de conhecimento, e por elementos empíricos extraídos da história de vida, da observação, e da classificação, que se unificavam numa prática ainda incompleta em suas possibilidades, porém inquestionável. Ao lado da medicina clínica, desenvolviase a medicina social, que unia elementos da clínica e fenômenos observados e registrados estatisticamente, com a análise de hábitos e padrões de consumo e higiene da população, entre outras matérias.

Apesar das diferenças era permitido pensar que as distintas medicinas existentes tinham uma certa unicidade. Essa unicidade procurava ser transmitida nas universidades, nos colégios médicos e nos hospitais. As teorias totalizantes existentes na época (do funcionalismo ao marxismo) reificavam sempre a idéia de "todo e de parte" e era sempre possível ao bom profissional verificar que sua especialidade tinha uma correspondência harmônica com a totalidade das ciências médica.

A partir dos anos sessenta e setenta, o advento de novas técnicas imprimiu um novo ritmo a especialização médica. O mercado de trabalho e suas novas formas heterônomas de vinculação com o setor público ou com as empresas médicas exigem do médico recém formado uma especialização crescente. Pouco valor passa a ter o tradicional "clínico geral" no mercado de trabalho. Com isso, as próprias universidades passaram a formar especialistas e desvalorizar uma sólida formação teórica, mesmo que respaldada no conceito de totalidade.

Os novos profissionais médicos que surgem a partir destas mudanças, 
têm como preocupação básica a cota de informação e conhecimento especffico de que necessitam para tirar o máximo de proveito de sua profissão. Sua linguagem torna-se distinta da de outros especialistas, com quem mantém um campo semântico minimamente comum para que seus clientes possam tramitar no interior dos serviços de saúde.

Esse "esfacelamento da linguagem" médica decorrente da especialização adiciona-se aos novos segmentos de linguagem trazidos pelas formas alternativas de medicina em todos os seus matizes. Mas independentemente da perplexidade dos que choram pela totalidade perdida, o conhecimento médico avança fazendo pontes e rupturas, ou criando elos semânticos entre as distintas linguagens que povoam o horizonte da ciência e do conhecimento em medicina.

Cabe, porém, uma advertência. O discurso em torno da totalidade tem vantagens e desvantagens. Uma das vantagens consiste em sua facilidade de transmissão e de aceitação, dado que ele cria sempre um efeito (real ou ilusório) de controle sobre o desconhecido. A desvantagem reside no fato de que, ao ser uma "camisa de força" sobre a realidade, este discurso inibe a criatividade e a intuição como forma de pensar a solução de problemas inusitados. 